\title{
Effect of The Heat Treatment on The Bioactivity of Nanostructured Surfaces
}

\author{
Vojtěch Hybášek, Jaroslav Fojt, Zdeněk Kačenka, Petra Jarolímová, Eva Průchová \\ University of Chemistry and Technology Prague, Technicka 5, 16628 Praha 6, Czech Republic, hybasekv@vscht.cz, \\ fojtj@vscht.cz, jarolime@vscht.cz,pruchovv@vscht.cz
}

\begin{abstract}
Titanium and its alloys are widely used materials in implantology due to their high corrosion resistance and biocompatibility. The bioactivity and the osseointegration of these surfaces could be enhanced by several processes. One of them is the formation of nanostructure by the combination of electrochemical and chemical reactions. The nanotubular oxidic structure has positive influence on the precipitation of hydroxyapatite from the body environment and on the cell proliferation. Directly created layer has amorphous character, but it is possible to transform it to crystalline form by heat treatment. This could have another positive influence on bioactivity. The influence of surfaces nanostructuring of commercially pure titanium and experimental beta alloy Ti-39Nb and their subsequent heat treatment on bioactivity will be presented in this work. This has been evaluated by Ca-P based compounds precipitation on the surface during the in vitro exposure in simulated body fluid. It was found that heat treatment has considerable influence on surface bioactivity.
\end{abstract}

Keywords: beta-titanium, nanotubes, hydroxyapatite, impedance, heat treatment

\section{Introduction}

Titanium and its alloys are widely used materials in orthopaedics and dentistry [1]. The use of metallic materials as artificial replacements (e.g. hip or knee joints) lead to the bone hard tissue replacement by a material with significantly higher modulus of elasticity. This intervention can cause a problem called "stress-shielding effect" [2-4]. The bone tissue begins to be nourished and regenerated inadequately, which may lead to a loss of mechanical integrity of the implant with bone [5]. To solve these problems, the new generation of less-problematic low modulus beta-titanium ( $\beta$-Ti) alloys has been developed [5]. These materials are particularly alloyed by $\mathrm{Zr}$, $\mathrm{Nb}$, Ta, Mo. Their Young's modulus is around $60 \mathrm{GPa}$. These types of alloys have excellent corrosion resistance and stability in biological environments [5-7].

Surface nanostructuring can be used to enhance the bioactivity of the materials surface. Many studies have been focused on a development and optimization of selforganised $\mathrm{TiO}_{2}$ nanotubes onto $\mathrm{Ti}$ substrates formation [8-10]. Electrochemical oxidation is one of the possibilities [11-14]. Nanotubes have positive influence on cells osteogenic differentiations, adhesion and proliferation [15-18]. The nanotubes heat treatment lead to the partial conversion of the amorphous titania to anatase or rutile form. The heat treatment at $300^{\circ} \mathrm{C}$ cause the transformation of amorphous oxide to the anatase phase. When the temperature rises to $600^{\circ} \mathrm{C}$, the anatase transforms to rutile [19]. Also the temperature above $400{ }^{\circ} \mathrm{C}$ leads to the removal of fluorides from the nanostructure. At $700^{\circ}$ $\mathrm{C}$, almost all anatase is converted to rutile (about 88\%) and the destruction of the nanotubes walls occur. At a temperature above $800^{\circ} \mathrm{C}$, the structure is destroyed [20, 21]. The anatase phase of $\mathrm{TiO}_{2}$ is much more effective in the growth of hydroxyapatite than the rutile phase. This is due to the more appropriate arrangement of the crystalline grid [22]. The basic requirement for implant materials is the formation of apatite on the surface. If apatite forms on the surface, it means that the material is potentially bioactive. This apatite formation may be studied in simulated body fluid (SBF) [23, 24].

The aim of this study is focused on surface parameters influence on the bioactivity (hydroxyapatite precipitation) of titanium beta alloy. Heat treated surfaces were also studied.
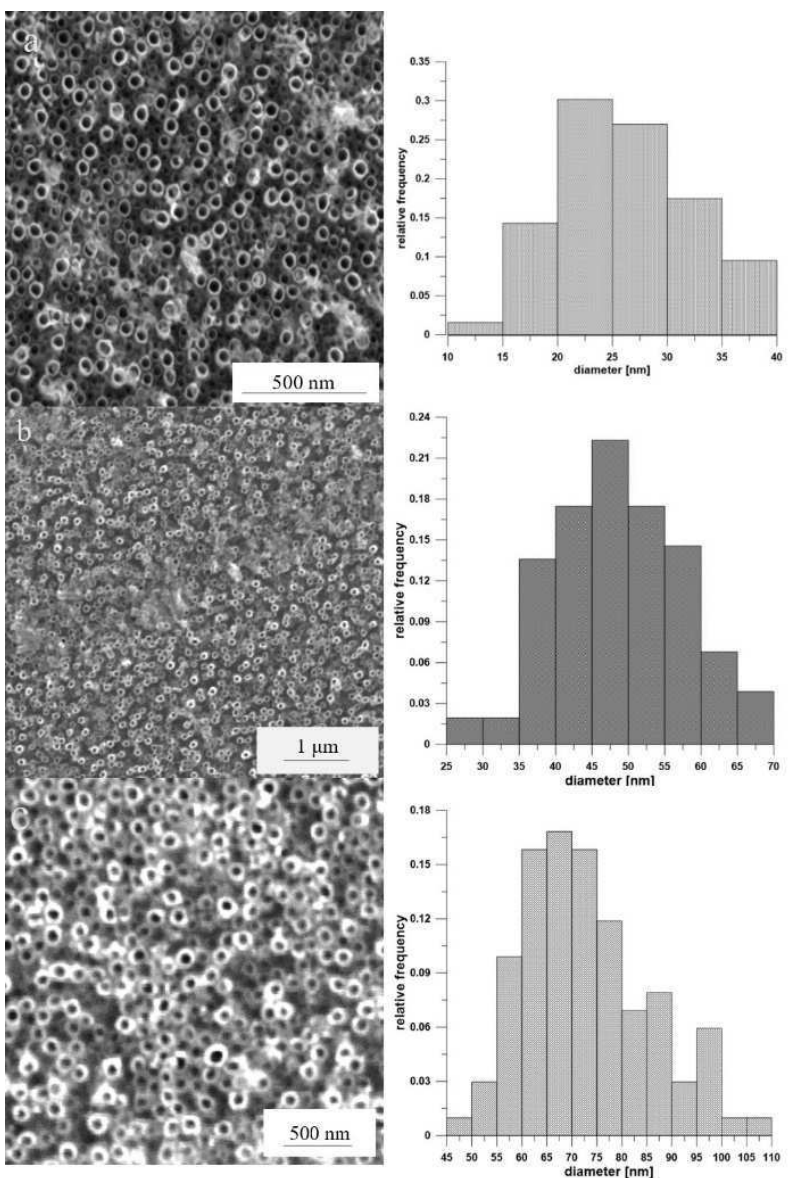

Fig. 1 nanostructures prepared at a) $10 \mathrm{~V}$; b) $20 \mathrm{~V}$; c) $30 \mathrm{~V}$ and relative proportion of their diameters 


\section{Experimental}

\subsection{Materials}

Experiments were conducted with specimens of Ti$39 \mathrm{Nb}$ alloy (UJP Prague). For electrochemical measurements, specimens of cylindrical shape (diameter $16 \mathrm{~mm}$, thickness $3 \mathrm{~mm}$ ) were wet ground (up to FEPA P4000 paper) and polished. Samples were sonicated in deionised water, ethanol and acetone, and then dried in an air stream before exposure. One set of the specimens were heat treated at $500^{\circ} \mathrm{C}$ for 120 minutes and cooled at laboratory temperature.

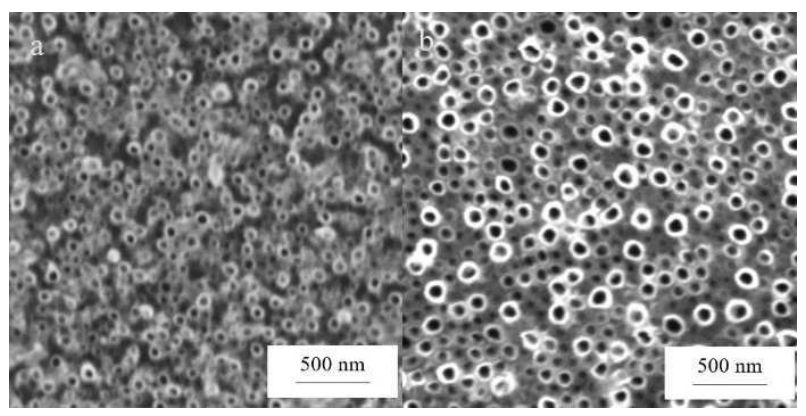

Fig. 2 nanostructures prepared at a) $20 \mathrm{~V}$; b) $30 \mathrm{~V}$ after heat treatment

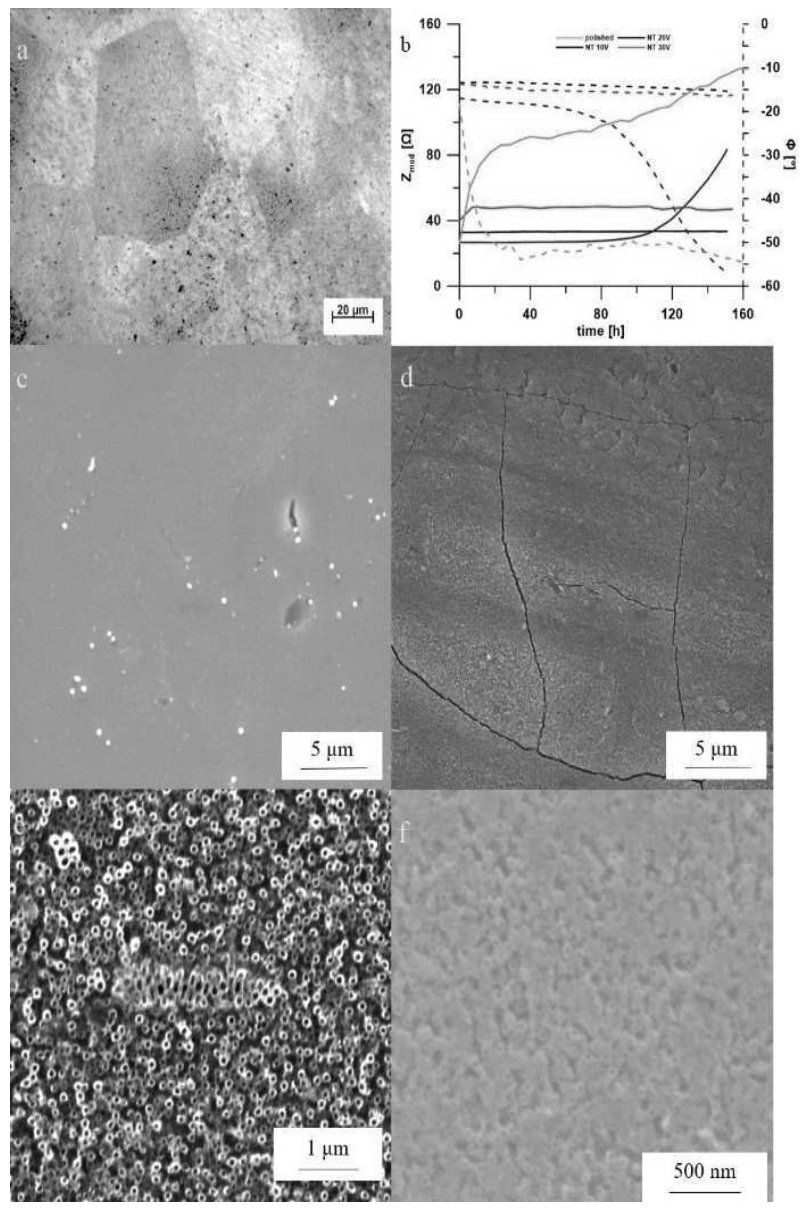

Fig. 3 a) metallographic cut-out after heat treatment; b) impedance module and phase dependence on time for specimens without heat treatment; non-treated specimens after exposure in SBF polished (c) and nanostructured at (d) $10 \mathrm{~V}$, (e) $20 \mathrm{~V}$, (f) $30 \mathrm{~V}$
Nanostructuring by anodic oxidation was realised in an electrolyte containing $1 \mathrm{~mol} \mathrm{l}^{-1} \mathrm{H}_{3} \mathrm{PO}_{4}$ and 0.6 wt. \% $\mathrm{NaF}$. Experiments were carried out using a standard three electrode setup with platinum gauze as a counter electrode, the sample as a working electrode and a silver/silver chloride $\left(3 \mathrm{~mol} \mathrm{l}^{-1} \mathrm{KCl}\right)$ reference electrode (SSCE). All potentials presented in this paper are related to this electrode. The electrochemical setup consisted of a potential ramp from the open circuit potential to the preselected potential $(10 \mathrm{~V}, 20 \mathrm{~V}, 30 \mathrm{~V})$ with a $10 \mathrm{mV} \mathrm{s}^{-1}$ sweep rate and subsequently by holding the potential for $4,000 \mathrm{sec}-$ onds. The potentiostatic exposure was followed by a potentiodynamic polarisation to the open circuit potential (rate $10 \mathrm{mV} \mathrm{s}^{-1}$ ). All anodization experiments were carried out at room temperature. After the anodization, the samples were ultrasonicated in deionised water and dried in an air stream. A high voltage potentiostat, the Jaissle Potenciostat-Galvanostat IMP 88 PC-200V with the PGU-AUTO Extern controlling unit was used in this work.

The bioactivity was studied in simulated body fluid prepared according to Kokubo [21]. All experiments were realised at $37^{\circ} \mathrm{C}$. The electrochemical impedance response at $2 \mathrm{kHz}$ was recorded during $168 \mathrm{~h}$ of the exposure. The precipitation of the new layer was detected by changes in the measured impedance response. For the morphological characterisation of the samples and surface evaluation after exposure, a scanning electron microscope (SEM) (TESCAN VEGA3) was used.

\section{Results and Discussion}

\subsection{Surface characterisation}

Prepared nanotubes as well as tubes diameters histograms are shown in Fig. 1 - Fig.6. There is an evident correlation between tubes diameters and anodic voltage. The tubes diameter increases with an increasing voltage. The tubes length was evaluated from side view and varying from $433 \pm 22 \mathrm{~nm}(10 \mathrm{~V})$, through $2.1 \pm 0.05 \mu \mathrm{m}(20 \mathrm{~V})$ to $3.1 \pm 0.05 \mu \mathrm{m}(30 \mathrm{~V})$. The tubes length is closely associated with an exposure time. With increased finale voltage, the exposure time is increasing and thus the tubes length is higher. Examples of the surface after the heat treatment are shown in Fig. 7 and Fig. 8. The nanotubes were not destroyed and tubes parameters remained the same. The temperature was chosen with respect to our previous research [14]. However, the beta phase decomposition occurred during the heat treatment. The alpha or omega phase (black points) was detected in microstructure (Fig. 9).

\subsection{Exposure tests in SBF}

The single frequency impedance data are shown in Fig. 10. The impedance modulus is increasing and phase angle decreasing during the exposure in the case of polished sample.

However, these changes were not caused by the precipitation of the layer but by the surface remodelling. The native passive layer is not stable on freshly polished sample. The oxide thickness is increasing during exposure and it caused this impedance response. 

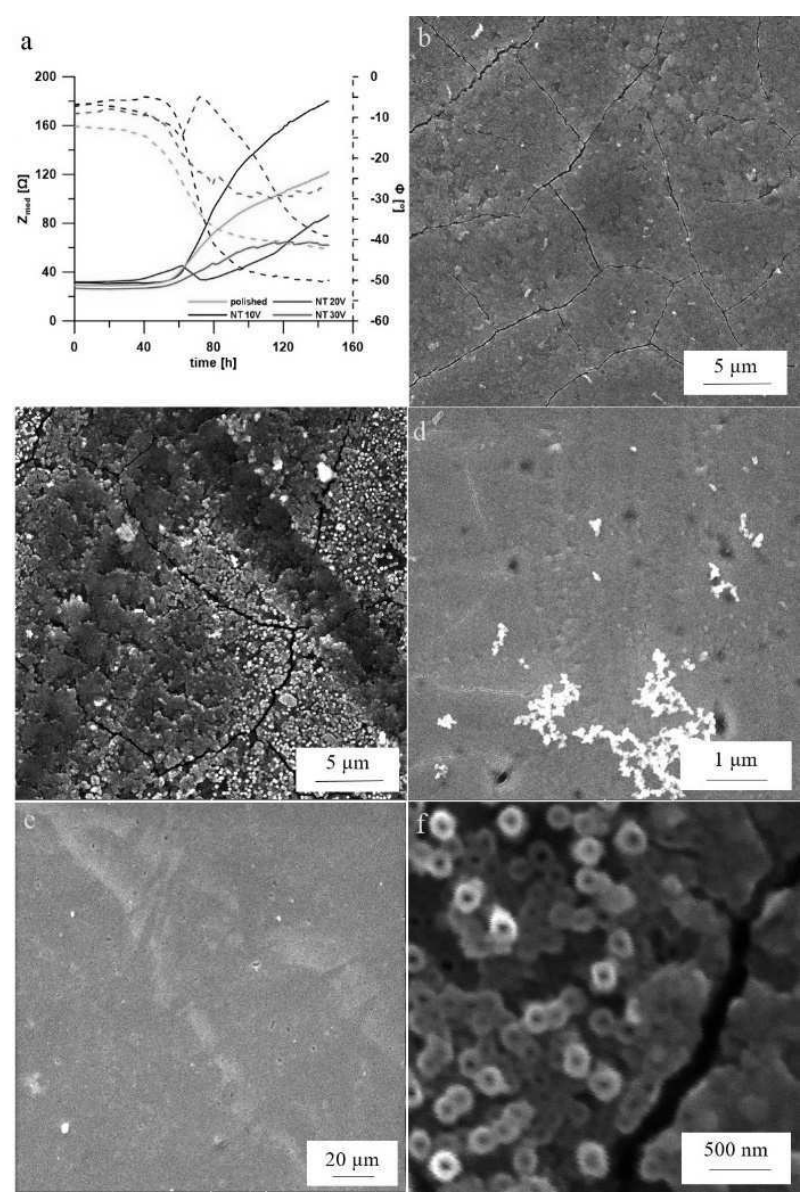

Fig. 4 a) impedance module and phase dependence on time for heat treated specimens; specimens after heat treatment and exposure in SBF with nanostructured at $10 \mathrm{~V}(\mathrm{~b}), 20 \mathrm{~V}(\mathrm{c}), 30 \mathrm{~V}(\mathrm{~d})$ and polished (e)surfaces; f) detail of $30 \mathrm{~V}$ nanostructure

A different situation occurred in the case of nanotubes. There are no possible changes of the surface after nanostructuring. The stability of the nanotubes is documented by the impedance response of that prepared at $10 \mathrm{~V}$ and $30 \mathrm{~V}$. The impedance change after approximately 100 $\mathrm{h}$ in the case of $20 \mathrm{~V}$ nanotubes was caused by a new layer precipitation. This was also confirmed by SEM (Fig. 12Fig. 15). The nanotubes were completely covered by the new layer composed mainly of $\mathrm{Ca}$ and $\mathrm{P}$ only in the case of $20 \mathrm{~V}$ specimen. It seems that $20 \mathrm{~V}$ tubes diameter is the most supportive for Ca-P layer creation because there is most of the precipitation centres.

The impedance time dependencies for heat treated specimens are shown in Fig. 11. There are evident changes in trend in the case of all surfaces. The Ca-P layer precipitation occurred on the all surfaces. The incubation period i.e. time to beginning of the layer precipitation was approximately 60 hours for polished, $10 \mathrm{~V}$ and $30 \mathrm{~V} \mathrm{spec-}$ imens. The incubation period for the $20 \mathrm{~V}$ specimen was about 40 hours. It is almost twice faster than in the case of specimen without heat treatment.

The surfaces of specimens after exposure are shown in Fig. 16 - Fig. 19. The surface was completely covered by the new layer in all cases. The EDS analysis confirmed the mixture of calcium phosphates. However, the more accurate analysis has to be done for the precise determination of the layer composition. The detail SEM picture clearly shows that the Ca-P layer copies the original nanostructure (Fig. 20).

\section{Conclusion}

The nanotubes on $\mathrm{Ti}-39 \mathrm{Nb}$ alloy surface were successfully prepared. The tubes diameter increased with increasing anodic voltage also the tubes length increased with time duration of the anodization process. The exposure test showed influence of tubes parameters on the Ca$P$ layer precipitation from simulated body fluid. The most perspective diameter was approximately $40 \mathrm{~nm}$. The appropriate heat treatment leads to increasing bioactivity of nanotubes. The Ca-P layer precipitation occurred on all treated surfaces. The shortest incubation period was noticed in the case of tubes with approximately $40 \mathrm{~nm}$ diameter. The single frequency impedance measurement seems to be a useful tool for surface processes monitoring.

\section{Acknowledgement}

The work was carried out as a part of the 16-14758S project, which is financially supported by Czech Science Foundation.

\section{References}

[1] FOUSOVA M, VOJTECH D. (2017) Influence of Process Conditions on Additive Manufacture of Ti6Al4V Alloy by SLM Technology. In: Manufacturing Technology, Vol. 17, No. 5, pp. 696-701. J. E. Purkyne University in Usti n. Labem, Czech Republic.

[2] FROST, H.M. (1994). Wolff's Law and bone's structural adaptations to mechanical usage: an overview for clinicians. In: The Angle Orthodontist, Vol, 64, No. 3, pp. 175-188. Edward H. Angle Society of Orthodontists, USA.

[3] BAHRAMINASAB, M., et al. (2012). Aseptic loosening of femoral components - A review of current and future trends in materials used. In: $M a-$ terials \& Design, Vol. 42. pp. 459-470. Elsevier Sci Ltd, England.

[4] BAHRAMINASAB, M., et al. (2013). Aseptic loosening of femoral components - Materials engineering and design considerations. In: Materials \& Design, Vol. 44, pp. 155-163. Elsevier Sci Ltd, England.

[5] CHAN, C.-W., et al. (2016). Enhancement of wear and corrosion resistance of beta titanium alloy by laser gas alloying with nitrogen. In: Applied Surface Science, Vol. 367, pp. 80-90. Elsevier Science Bv, Netherlands.

[6] TANAKA, Y., et al. (2008). Characterization of air-formed surface oxide film on $\mathrm{Ti}-29 \mathrm{Nb}-13 \mathrm{Ta}-$ 4.6Zr alloy surface using XPS and AES. In: 
Corrosion Science, Vol. 50, No.8, p. 2111-2116. Elsevier Sci Ltd, England.

[7] OKAZAKI, Y. and E. Gotoh (2005). Comparison of metal release from various metallic biomaterials in vitro. In: Biomaterials, Vol. 26, pp. 11-21. Elsevier Sci Ltd, England.

[8] MACAK, J.M. and P. SCHMUKI (2006) Anodic growth of self-organized anodic $\mathrm{TiO} 2$ nanotubes in viscous electrolytes. In: Electrochimica Acta, Vol. 52, No. 3, pp. 1258-1264. Elsevier Sci Ltd, England.

[9] MACAK, J.M., et al. (2007) Multilayer TiO2-nanotube formation by two-step anodization. In: Electrochemical and Solid State Letters, Vol. 10, No.7, pp. K28-K31. Electrochemical Soc Inc, USA.

[10] FOJT, J., (2012) Ti-6Al-4V alloy surface modification for medical applications. In: Applied Surface Science, Vol. 262, pp. 163-167. Elsevier Science Bv, Netherlands.

[11] MACAK, J.M., et al. (2005). Self-organized nanotubular oxide layers on $\mathrm{Ti}-6 \mathrm{~A} 1-7 \mathrm{Nb}$ and $\mathrm{Ti}-6 \mathrm{~A} 1-$ $4 \mathrm{~V}$ formed by anodization in NH4F solutions. In: Journal of Biomedical Materials Research Part A, Vol. 75A, No. 4, pp. 928-933. Wiley-Blackwell, USA.

[12] FOJT, J., V. HYBASEK, and L. JOSKA (2016) Electrochemical behaviour of the nanostructured surface of Ti-35Nb-2Zr alloy for biomedical applications. In: Materials and Corrosion, Vol. 67, No. 9, pp. 915-920. Wiley-V C H Verlag GmbH, Germany.

[13] FERREIRA, C.P., et al. (2013) Effects of substrate microstructure on the formation of oriented oxide nanotube arrays on Ti and Ti alloys. In: Applied Surface Science, Vol. 285, Part B, pp. 226-234. Elsevier Science Bv, Netherlands.

[14] GHICOV, A., et al. (2006) TiO2-Nb2O5 nanotubes with electrochemically tunable morphologies. In: Angewandte Chemie-International Edition, Vol. 45, No. 42, pp. 6993-6996. Wiley-V C H Verlag $\mathrm{GmbH}$, Germany.

[15] MORAVEC, H., et al. (2016) Cell interaction with modified nanotubes formed on titanium alloy $\mathrm{Ti}$ 6Al-4V. In: Materials Science and Engineering: $C$, Vol. 65, pp. 313-322. Elsevier Science Bv, Netherlands.
[16] STAN, M.S., et al. (2015) Effects of titaniumbased nanotube films on osteoblast behavior in vitro. In: J Biomed Mater Res A, Vol. 103 No. 1, pp. 48-56.

[17] FILOVA, E., et al. (2015). The diameter of nanotubes formed on Ti-6Al-4V alloy controls the adhesion and differentiation of Saos- 2 cells. In: International Journal of Nanomedicine, pp. 7145. Dove Medical Press Ltd, New Zealand

[18] TAN, A.W., et al. (2012) Review of titania nanotubes: Fabrication and cellular response. In: Ceramics International, Vol. 38, No. 6, pp. 4421-4435. Elsevier Sci Ltd, England.

[19] ALHOSHAN, M.S., et al. (2012). Heat treatment and electrochemical activation of titanium oxide nanotubes: The effect of hydrogen doping on electrochemical behavior. In: Electrochimica Acta, Vol. 62, pp. 390-395. Elsevier Sci Ltd, England.

[20] YU, J. and B. WANG (2010). Effect of calcination temperature on morphology and photoelectrochemical properties of anodized titanium dioxide nanotube arrays. In: Applied Catalysis B: Environmental, Vol. 94 No. 3-4, pp. 295-302. Elsevier Science Bv, Netherlands.

[21] NOVAK, P., SALVETR, P., BERNATIKOVA A., VOJTECH D. (2016). Termochemical Treatment of Non-Ferrous Alloys. In: Manufacturing Technology, Vol. 16 No. 5, pp. 1100-1102. J. E. Purkyne University in Usti n. Labem, Czech Republic.

[22] OH, S.-H., et al. (2005). Growth of nano-scale hydroxyapatite using chemically treated titanium oxide nanotubes. In: Biomaterials, Vol. 26 No. 24, pp. 4938-4943. Elsevier Sci Ltd, England.

[23] KOKUBO, T. and H. TAKADAMA (2006). How useful is SBF in predicting in vivo bone bioactivity? In: Biomaterials, Vol. 27, No. 15, pp. $2907-$ 2915. Elsevier Sci Ltd, England.

[24] POSPISILOVA I., MSALLAMOVA S.,VOJTECH D. (2015). Testing of Zn-1.6Mg Alloy in Physiological Solution In: Manufacturing Technology, Vol. 15, No. 6, pp. 1032-1036. J. E. Purkyne University in Usti n. Labem, Czech Republic. 